\title{
The genetic basis of color-related local adaptation in a ring-like colonization around the Mediterranean
}

\author{
Reto Burri, ${ }^{1,2, *}$ Sylvain Antoniazza, ${ }^{3,4, *}$ Arnaud Gaigher, ${ }^{5}$ Anne-Lyse Ducrest, ${ }^{3}$ Céline Simon, ${ }^{3}$ The European \\ Barn Owl Network, ${ }^{6}$ Luca Fumagalli, ${ }^{5}$ Jérôme Goudet, ${ }^{3, \dagger}$ and Alexandre Roulin ${ }^{3, \dagger}$ \\ ${ }^{1}$ Department of Evolutionary Biology, Evolutionary Biology Centre, Uppsala University, Norbyvägen 18D, SE-75236 \\ Uppsala, Sweden \\ ${ }^{2}$ E-mail: burri@wildlight.ch \\ ${ }^{3}$ Department of Ecology and Evolution, University of Lausanne, Biophore, CH-1015 Lausanne, Switzerland \\ ${ }^{4}$ Swiss Ornithological Institute, Seerose 1, CH-6204 Sempach, Switzerland \\ ${ }^{5}$ Laboratory for Conservation Biology, Department of Ecology and Evolution, University of Lausanne, Biophore, CH-1015 \\ Lausanne, Switzerland
}

${ }^{6}$ Members and affiliations of this group author are listed in the Supplementary Information

\author{
Received January 19, 2015
}

Accepted November 9, 2015

\begin{abstract}
Uncovering the genetic basis of phenotypic variation and the population history under which it established is key to understand the trajectories along which local adaptation evolves. Here, we investigated the genetic basis and evolutionary history of a clinal plumage color polymorphism in European barn owls (Tyto alba). Our results suggest that barn owls colonized the Western Palearctic in a ring-like manner around the Mediterranean and meet in secondary contact in Greece. Rufous coloration appears to be linked to a recently evolved nonsynonymous-derived variant of the melanocortin 1 receptor (MC1R) gene, which according to quantitative genetic analyses evolved under local adaptation during or following the colonization of Central Europe. Admixture patterns and linkage disequilibrium between the neutral genetic background and color found exclusively within the secondary contact zone suggest limited introgression at secondary contact. These results from a system reminiscent of ring species provide a striking example of how local adaptation can evolve from derived genetic variation.
\end{abstract}

KEY WORDS: Barn owl, clines, local adaptation, melanin-based coloration, ring species.

Phenotypic variation is widespread in natural populations, and understanding how ecology-driven selection contributes to its evolution and maintenance is a central task in evolutionary biology. The demonstration of an involvement of selection in phenotypic evolution represents only a first step to this end, and leaves a wealth of questions concerning the origin, maintenance, and consequences of phenotypic variation. What are the agents of selection? When did alternative phenotypes evolve? May new phenotypes enable the colonization of new ranges? In such cases, can geographic

\footnotetext{
${ }^{*}$ These authors are joint first authors.
}

${ }^{\dagger}$ These authors are joint senior authors. isolation, ecology-driven ecological selection, or their interplay lead to ecological speciation (Nosil 2012)?

To gain a better understanding of these questions, insights into the phenotypes' ecology and the genetics underlying phenotypic variation are required. The ecological function of a phenotypic trait can point toward potential selective agents to be investigated, and may in some cases identify traits correlated to the focal phenotype that may be the targets of selection in its stead (e.g., Stearns 1992). Especially for complex phenotypes that may mirror multiple functions, such as melanin-based coloration (Ducrest et al. 2008), identifying the actual target of selection can pose challenges. Identifying the gene(s) underlying the observed 
phenotypic variation may provide important clues in this context, by providing information about the extent of alternative target traits linked via pleiotropy. Moreover, the population genetic study of these genes can help corroborate the evidence for the adaptive evolution of the phenotype of interest, and may provide insights into the relative ages of alternative phenotypes. The integrative study of species' colonization history, ecology, and quantitative trait locus (QTL) variation therefore offers opportunities to further our understanding of the role of novel genetic and phenotypic variation for the colonization of new ranges, and ultimately species formation.

Barn owls (Tytonidae) of the genus Tyto represent an ideal system to tackle these questions. These birds exhibit extraordinary examples of phenotypic variation, with pheomelanin-based plumage color clines across continents found in at least seven (sub)species (Roulin et al. 2009). The strongest cline is found in the European barn owl (Tyto alba), which varies from white in Iberia to dark rufous in Northeastern Europe (Roulin 2003; Antoniazza et al. 2010). The pronounced phenotypic population structure of this color cline contrasts with a significantly weaker pattern of isolation by distance observed at the neutral genetic level within Europe (Antoniazza et al. 2010). Spatially explicit modeling provides evidence that the species' European range was colonized in a single expansion out of Iberia following the last glaciation, and indicates that the color cline did not evolve as a neutral by-product of colonization (Antoniazza et al. 2014). These two lines of evidence strongly suggests that the barn owl color polymorphism is maintained by selection (Antoniazza et al. 2010, 2014), and correlations of coloration with other phenotypes may reinforce the pattern of color-related local adaptation.

Differences in the ecology correlated with color phenotypes indicate that rufous individuals are better adapted to the continental environment prevailing in Northeastern Europe (Antoniazza et al. 2010): Rufous owls more often exploit open habitats than white owls, and feed predominantly on voles rather than murids (Roulin 2004; Charter et al. 2012). Females choose specific breeding habitats that match their color phenotype, with rufous females producing more offspring in open habitats and white females more offspring in woodier habitats (Dreiss et al. 2012). Rufous males make higher reproductive investments and sire more fledglings in some years (Roulin et al. 2001). Rufous juveniles develop better with limited food conditions (Roulin et al. 2008) and show more altruistic behavior than nonrufous juveniles (Roulin et al. 2012). Moreover, several studies link rufous coloration to increased juvenile dispersal distance (Van den Brink et al. 2012; Roulin 2013) and phenotypic traits enhancing longdistance flight (longer wings, Roulin 2004; Charter et al. 2012) and intense flying (Charter et al. 2015), and may suggest that rufous coloration is connected to a disperser phenotype.

Because of the correlations of coloration with other phenotypes and the strong pleiotropy of the melanocortin system that underlies melanin-based coloration (Ducrest et al. 2008), conclusive evidence for the selective target(s) and agent(s) establishing the European barn owl color cline is lacking. Identifying the gene(s) underlying barn owl plumage coloration and their extent of pleiotropy may therefore provide clues to determine whether selection in the European barn owl color cline acts on coloration itself or instead may rather target one of the correlated life-history traits. Also, the so far restricted sampling of the species range-which does not include Southeastern Europe, the Middle East, and North Africa-precludes ultimate conclusions about the range-wide colonization history under/following which the cline evolved, because incomplete phylogeographic sampling may result in misleading conclusions about colonization histories (see, e.g., Yannic et al. 2012). Studying the evolution of color phenotypes and the underlying genetic variants in the context of the species' range-wide colonization history therefore promises to provide important insights into both the origin and evolutionary history of barn owl color phenotypes, and possible genome-wide consequences of ecology-driven selection.

Here, we investigated genetic data from 22 microsatellite markers and a mitochondrial marker (NADH dehydrogenase 6 gene, $N D 6$ ) together with data on melanin-based coloration and from a candidate color gene (melanocortin 1 receptor, $M C 1 R$ ) in an extensive sampling of $>700$ European barn owls (T. alba) from 28 populations from Europe, North Africa, and the Middle East. We (i) reconstructed the circum-Mediterranean colonization history of barn owls, (ii) identified a major QTL underlying barn owl plumage coloration and studied the levels of variation linked to this QTL variant, and (iii) contrasted the population structure of coloration and of the color QTL with neutral genetic population structure to infer the role of selection in the evolution of the barn owl color cline.

\section{Methods}

\section{SAMPLING AND MOLECULAR ANALYSES}

The study includes 724 unrelated barn owls from 28 different localities around the Mediterranean and throughout Europe (Fig. 1, Table S1). Genomic DNA was extracted from the basal millimeter of breast feather quills, or from blood or muscle stored in $96 \%$ ethanol. DNA extractions were performed on a BioSprint 96 extraction robot using the BioSprint 96 DNA blood kit, or the DNeasy Blood and Tissue Kit (Qiagen, Hilden, Germany). Sex was determined using the molecular method by Py et al. (2006).

All 724 individuals were genotyped at 22 microsatellites with no evidence for null alleles and no constant deviation from HardyWeinberg equilibrium (Table S2) (Burri et al. 2008; Klein et al. 2009). The same loci were genotyped in outgroup populations from California, USA (T. a. pratincola, $N=65$ ), Australia ( $T$. a. delicatula, $N=19$ ), and Singapore (T. a. javanica, $N=11$ ). For 456 individuals plus 24 individuals from California $(N=8)$, 
A

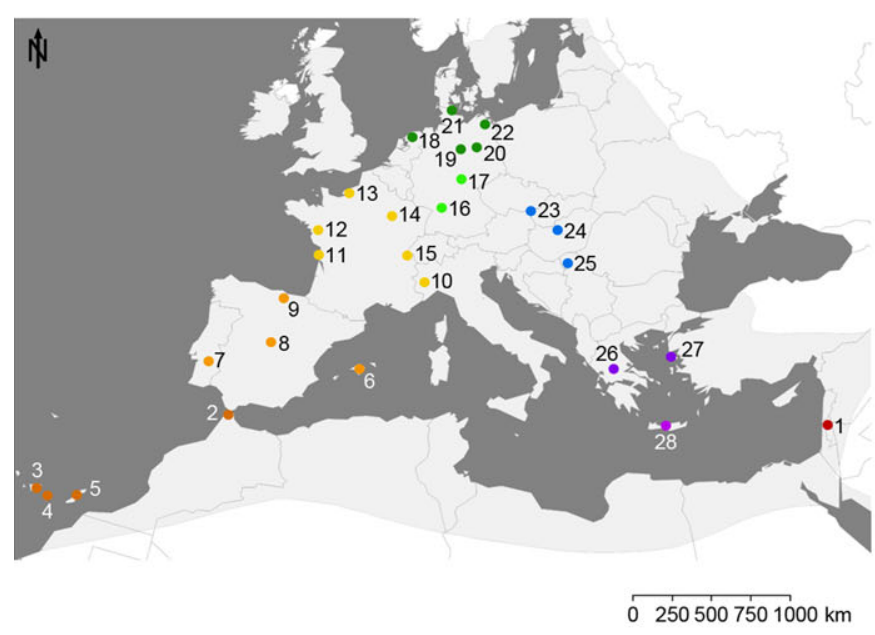

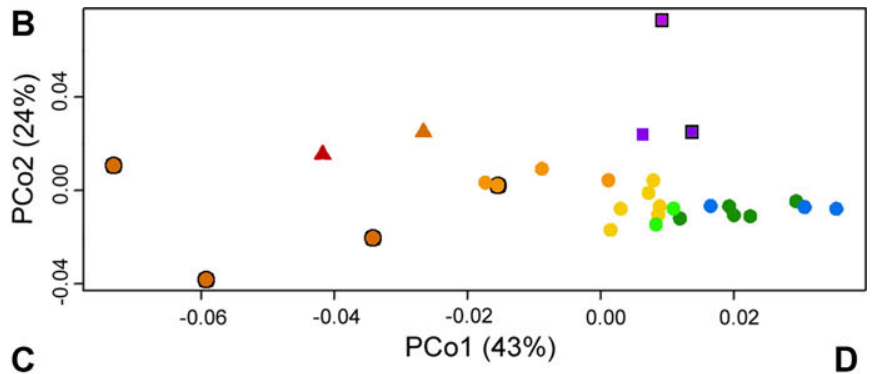

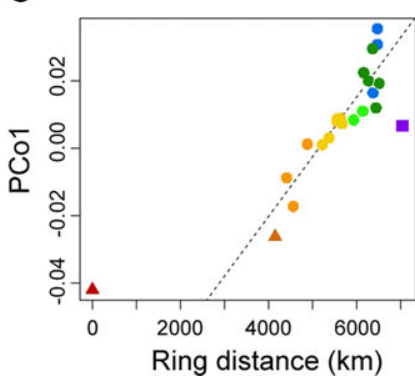

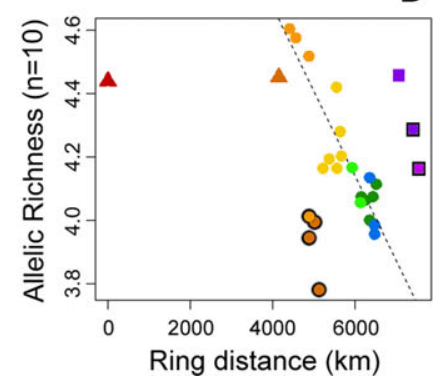

Figure 1. Sampling and population structure. (A) Geographic distribution of sampling locations of barn owls. The distribution of barn owls in the study range is shaded in light gray. 1, Middle East; 2, North Africa; 3, Tenerife; 4, Gran Canaria; 5, Eastern Canaries (Lanzarote, Fuerteventura); 6, Baleares; 7, Portugal; 8, Central Spain; 9, Northern Spain; 10, Italy; 11, France La Rochelle; 12, France Nantes; 13, Northern France; 14, Eastern France; 15, Switzerland; 16, Southern Germany; 17, Germany Sachsen; 18, Netherlands; 19, Germany Niedersachsen; 20, Germany Brandenburg; 21, Denmark; 22, Northeastern Germany; 23, Czech Republic; 24, Hungary; 25, Balkans; 26, Greece; 27, Aegean; 28, Crete. (B) PCOA based on microsatellite markers. Coloration follows (A). (C) Correlation of the first PCo axis of mainland populations with ring distance from the Middle East. The regression line is based on all European populations but Greece. (D) Geographic structure of microsatellite allelic richness. The regression line is based on all European mainland populations. (C) and (D): Greece, the Aegean, and Crete are depicted with squares, Middle Eastern and North African populations with triangles, islands in (D) with a black border.

Singapore $(N=8)$, and Australia $(N=8)$ a fragment of 411 bp of the mitochondrial ND6 gene was sequenced (Table S2).

Extensive studies in mammals and birds (reviewed in Hoekstra 2006; Roulin and Ducrest 2013) place the MCIR gene as a prime candidate gene responsible for melanin-based color polymorphisms. To study whether $M C 1 R$ variant explain color variation in barn owls, $543 \mathrm{bp}(N=211)$ or the whole $998 \mathrm{bp}$ $(N=417)$ of the single exon were sequenced for 671 individuals from Europe (Table S1), and outgroup individuals from California $(N=3)$, Australia $(N=1)$, and Singapore $(N=1)$ (Supporting Information Methods). For museum samples and some low-quality DNA samples amplification of these fragments was impossible $(N=43)$, and we used an allelic discrimination assay for the Val126Ile mutation (Supporting Information Methods).

Microsatellites were genotyped in Gene Mapper version 4.0 (Applied Biosystems, Zug, Switzerland). ND6 and MC1R sequences were assembled and edited in CodonCode Aligner version 3.7.1, and aligned using Clustal W (Thompson et al. 1994). $M C 1 R$ polymorphisms were phased using PHASE (Stephens et al. 2001) in DnaSP 5.10.01 (Librado and Rozas 2009) using 1000 burn-in and 1000 post-burn-in iterations and a thinning interval of 10. A neighbor net haplotype network of $M C 1 R$ alleles was constructed using SplitsTree 4.12.3 (Hudson and Bryant 2006).

\section{NEUTRAL GENETIC POPULATION STRUCTURE AND ADMIXTURE ANALYSES}

To infer neutral population structure and diversity, pairwise $F_{\mathrm{ST}}$ between populations and allelic richness $\left(A_{\mathrm{R}}\right)$ based on microsatellite and mitrochondrial data were estimated using hierfstat version 4-10 (Goudet 2005). The same package was used to perform principle coordinate analyses (PCoA) based on pairwise $F_{\mathrm{ST}}$. Patterns of isolation by distance inferred using Mantel tests were performed using ecodist 1.2.7 (Goslee and Urban 2007). A haplotype network for ND6 was constructed using TCS 1.21 (Clement et al. 2000) to infer population structure in haplotype frequencies. Haplotypes from California, Singapore, and Australia were disconnected from the European haplotype network and thus not included in the results.

Linear models were used to test whether population genetic structure (as estimated by PCo axes coordinates) and genetic diversity $\left(A_{\mathrm{R}}\right)$ are related to geographic proximity measured as (i) flight and (ii) shortest overland distance, or to (iii) ring distance (see Fig. S1 for an example). Flight distance and shortest overland distance were used, because barn owls have good flying abilities and colonized many far off-shore islands, but may still avoid crossing large water bodies. Ring distance was modeled as the shortest overland distance between populations within a 
clockwise ring starting in the Middle East and ending in Crete. Start and end points of the ring were determined from the population structure depicted by PCoA (Figs. 1B, S2). Note that even with a colonization origin in Iberia, this distance depicts the ring scenario with a break in population structure situated between Greece and the Middle East. Distances were measured in Google Earth.

To estimate the number of genetic clusters and admixture proportions for each individual, clustering analyses implemented in STRUCTURE 2.3.4 (Pritchard et al. 2000) were performed using microsatellite data at $K$ from $K=1$ to $K=10$. Analyses were run once for all populations, and once for mainland populations plus the Aegean exclusively. The latter was included with mainland populations because it was a focal population for admixture analyses and because of the Aegean islands' proximity to the mainland and their genetic diversity being very similar to the neighboring mainland population in Greece (all other island populations show much lower genetic diversity). Ten runs each with a burn-in of $10^{5}$ and $10^{6}$ post-burn-in generations were performed for each $K$ using an admixture model with correlated allele frequencies. The number of clusters was inferred using the $\Delta K$ method (Evanno et al. 2005) implemented in STRUCTURE HARVESTER (Earl and vonHoldt 2012).

To estimate which populations/clusters exhibit allele frequencies closest to outgroup populations from California, Australia, and Singapore, we performed three analyses. First, we estimated a neighbor-joining (NJ) population tree using $F_{\mathrm{ST}}$ and Cavalli-Sforza and Edwards chord distance (Cavalli-Sforza and Edwards 1967). Second, we ran STRUCTURE $\left(5 \times 10^{4}\right.$ burn-in, and $5 \times 10^{5}$ post-burn-in generations) including outgroup populations, and estimated $\mathrm{NJ}$ trees based on net nucleotide distance among clusters to infer the relationships between the inferred clusters. We ran 10 iterations for each $K$, and increased $K$ until no new cluster splitting off one or several populations was observed (at $K=7$ ). Three microsatellites showed more than $10 \%$ missing data in the outgroup populations, and were excluded from both analyses (Tak.Oeo53, Ta.305, Ta.408). As island populations showed increased differentiation relative to the other populations, and to avoid problems connected with long-branch attraction of the NJ method, they were excluded from both analyses. Third, we reconstructed the phylogenetic relationships among European, American, and Australasian (Singapore and Australia) ND6 haplotypes using MrBayes 3.2.5 (Ronquist et al. 2012). Haplotypes from Phodilus badius (Tytonidae; Genbank accession no. KF961183) and Otus elegans (Strigidae; Genbank accession no. EU123912) were included as outgroups. Two runs with four chains each were run for $2 \times 10^{6}$ generations, including $5 \times 10^{5}$ burn-in generations, using a GTR $+\mathrm{G}+$ I nucleotide substitution model. Convergence was evaluated based on the average standard deviation of split frequencies among runs (0.008).
To test whether the mean and variance in admixture proportions (as estimated using STRUCTURE with $Q=2$ ) observed in the secondary contact zone in Greece and the Aegean (see Results) differed significantly from those in other populations with similar admixture proportions (Portugal, Central and Northern Spain), we performed nonparametric bootstrap tests over individuals as described below. As we observed no significant differentiation of the populations identified as belonging to the secondary contact zone (Greece, Aegean), these populations were pooled for the following analysis. Random samples of the same size as the combined Greek and Aegean populations $(N=46)$ were drawn from the admixture proportion $(Q)$ distributions of the combined Iberian populations $(N=61$, these populations show the most similar admixture patterns to Greece). The same procedure was performed using the hybrid index (HI) (Buerkle 2005) instead of $Q$. For each analysis $10^{6}$ random samples were drawn with replacement to generate the expected distribution of the variance in admixture proportions. HI was estimated using the "introgress" package (Gompert and Buerkle 2010). To estimate HI, "southern" and "northeastern" parental populations were defined from STRUCTURE results, by using individuals with a respective $Q \geqq$ 0.97 and without missing data from Northern and Eastern Europe (northeastern lineage), and from the Middle East, Crete, and the Canary Islands (southern lineage), respectively. The northeastern parental population thus consisted of 78 individuals from the Netherlands $(N=10)$, Niedersachsen $(N=15)$, Brandenburg $(N$ $=8)$, Denmark $(N=14)$, Northeastern Germany $(N=8)$, Hungary $(N=11)$, Czech Republic $(N=4)$, and the Balkans $(N=8)$. The "southern" parental population consisted of 24 individuals from the Middle East $(N=5)$, Eastern Canaries $(N=6)$, and Crete $(N=13)$.

\section{MEASUREMENT AND QUANTITATIVE GENETICS ANALYSES OF COLOR PHENOTYPES}

Pheomelanin-based plumage color of 626 birds was measured from one to five breast feathers (mean: 4.15, SD: 1.08). Reflectance spectra from four points per feather were captured with a USB4000 spectrophotometer (Ocean Optics, Dunedin, FL) and a DH-2000-bal dual deuterium/halogen light source (Mikropackan, Ostfildern, Germany). For each reflectance spectrum, the brown chroma was calculated following Montgomerie (2006). For each individual, values were averaged per feather and then per individual. Color measurements were high repeatable (97.6\% of amongindividual variance), as shown by the repeated measurement in 14 individuals one year apart. Feathers are archived in the last author's collection.

To test whether color differentiation among populations evolved by genetic drift exclusively or whether local adaptation played a role in its evolution, we used two approaches. The first is derived from classic $F_{\mathrm{ST}}-Q_{\mathrm{ST}}$ comparisons (Merilä and Crnokrak 
2001; McKay and Latta 2002; Leinonen et al. 2008, 2013; Brommer 2011). We estimated $F_{\mathrm{ST}}$ as outlined above. $P_{\mathrm{ST}}$ (an analog of $Q_{\mathrm{ST}}$ based on phenotypic traits) for color differentiation was estimated using ANOVA with color as response variable and the populations of origin and sex as explanatory variables following Antoniazza et al. (2010). Variance components were then combined with the estimated heritability of coloration (Roulin and Dijkstra 2003). To estimate whether clinal variation in $M C 1 R$ genotypes differs from clinal variation in other genes involved in the expression of coloration, we also estimated $P_{\mathrm{ST}}$ after taking into account $M C 1 R$ genotype in a linear model. Following the general approach by Whitlock (2008), Whitlock and Guillaume (2009) proposed a parametric bootstrap approach to compare overall $Q_{\mathrm{ST}}$ and $F_{\mathrm{ST}}$. This approach was not applicable to our system in which quantitative measurements are field based, because it requires a resampling of the variance components of $Q_{\mathrm{ST}}$ from a quantitative genetics breeding design. We thus used the general idea of Whitlock's (2008) proposition and directly compared empiric $P_{\mathrm{ST}}$ estimates to the theoretical $\chi^{2}$ distribution of Lewontin and Krakauer (1973) to obtain a $P$-value for the $F_{\mathrm{ST}}-P_{\mathrm{ST}}$ comparison. $F_{\mathrm{ST}}$ estimates for $N D 6$ (divided by four to account for the difference of effective population size of mitochondrial markers) and for $M C 1 R$ were added for comparison. The second approach by Ovaskainen et al. (2011) compares Bayesian estimates of population differentiation at neutral genetic makers and quantitative traits. We applied this approach using the R packages RAFM (Karhunen and Ovaskainen 2012) and Driftsel (Karhunen et al. 2013).

\section{RELATING COLORATION TO MC1R POLYMORPHISM, GEOGRAPHY, AND NEUTRAL GENETIC ANCESTRY}

To investigate whether $M C 1 R$ polymorphism is associated with individual variation in pheomelanin-based coloration, linear models were estimated with coloration (brown chroma) as the response variable, and $M C 1 R$ genotype at amino acid position 126 and sex as factors $(M C 1 R$ variants at position 126 related to the white and rufous phenotype are referred to as $M C 1 R_{\text {RUFOUS }}$ and $M C 1 R_{\text {WHITE }}$, respectively). Models were estimated for the entire dataset, taking into account population structure using each individual's position on the first principal component from an individual-based principal component analysis (PCA) on neutral genetic diversity as a covariate, and for each population separately. PCA was conducted using the adegenet 1.3-7 R package (Jombart et al. 2008). Population structure for the nonsynonymous polymorphism at amino acid position 126 was estimated by calculating $F_{\mathrm{ST}}$ using hierfstat. We investigated how population structure at $M C 1 R$ correlated with color differentiation and spatial distances between populations using Mantel tests and partial Mantel tests as implemented in ecodist.
To test whether there were significantly more variable sites linked to $M C 1 R_{\text {WHITE }}$ (which was sampled more often) than to $M C 1 R_{\text {RUFOUS }}$, we applied a randomization test on all variation observed across the full sequence (10 polymorphic sites). Only sequences covering all variable sites were used for this analysis $\left(618 M C 1 R_{\text {WHITE }}, 252 M C 1 R_{\text {RUFOUS }}\right)$. Then, we randomly sampled 252 of the $618 M C 1 R_{\text {WHITE }}$ alleles for $10^{6}$ times. Each time we estimated the mean number of pairwise differences $(\pi)$ in the sample. The proportion of times the observed $\pi$ is larger than those generated by randomization is an estimate of the sought $P$-value.

To test for linkage disequilibrium of coloration with the neutral genetic background in the secondary contact zone, linear models were used to examine the hypothesis that within the secondary contact zone rufous individuals have an elevated proportion of neutral genetic ancestry from Northeastern Europe. As the populations from Greece and the Aegean are not genetically differentiated, they were combined for this analysis. Models included coloration (brown chroma) as a response variable, and sex, $M C 1 R$ genotype, and neutral genetic ancestry as explanatory variables. We used three approaches to estimate neutral genetic ancestry. The first models made use of the admixture proportions $(Q)$ attributed to the "Northeastern" cluster by STRUCTURE for mainland populations (including the Aegean). Second, ancestry was approximated by individuals' first principal axis score of an individual-based PCA (PCA eigenvalue of first axis = 5.7). The PCA was conducted in $\mathrm{R}$ using the adegenet 1.3-7 package. Third, neutral genetic ancestry was expressed in terms of the HI estimated as outlined above.

\section{Results \\ RING-LIKE POPULATION STRUCTURE AROUND THE MEDITERRANEAN}

Genetic differentiation among barn owl populations follows a shallow pattern of isolation by distance (overall $F_{\mathrm{ST}}$ : microsatellites, 0.045; ND6, 0.134) (Table 1, Fig. S3). Strongest differentiation on the mainland was identified between the populations in Eastern Europe and the Middle East, discordant with these populations' spatial proximity (microsatellite $F_{\mathrm{ST}}$ : HungaryMiddle East, 0.085; Balkans-Middle East, 0.084; Fig. S4A). PCoA showed the same close genetic proximity of the Middle Eastern population with the geographically distant populations from the Canary Islands, North Africa, and Iberia, while placing it most distant from the geographically closer populations in Eastern Europe (Figs. 1B, S2), suggesting ring-like colonization around the Mediterranean. This hypothesis is consistent with the geographic distribution of admixture proportions estimated in Bayesian analyses of population structure (Pritchard et al. 2000) (Fig. 2A, B). These analyses found highest support for two 


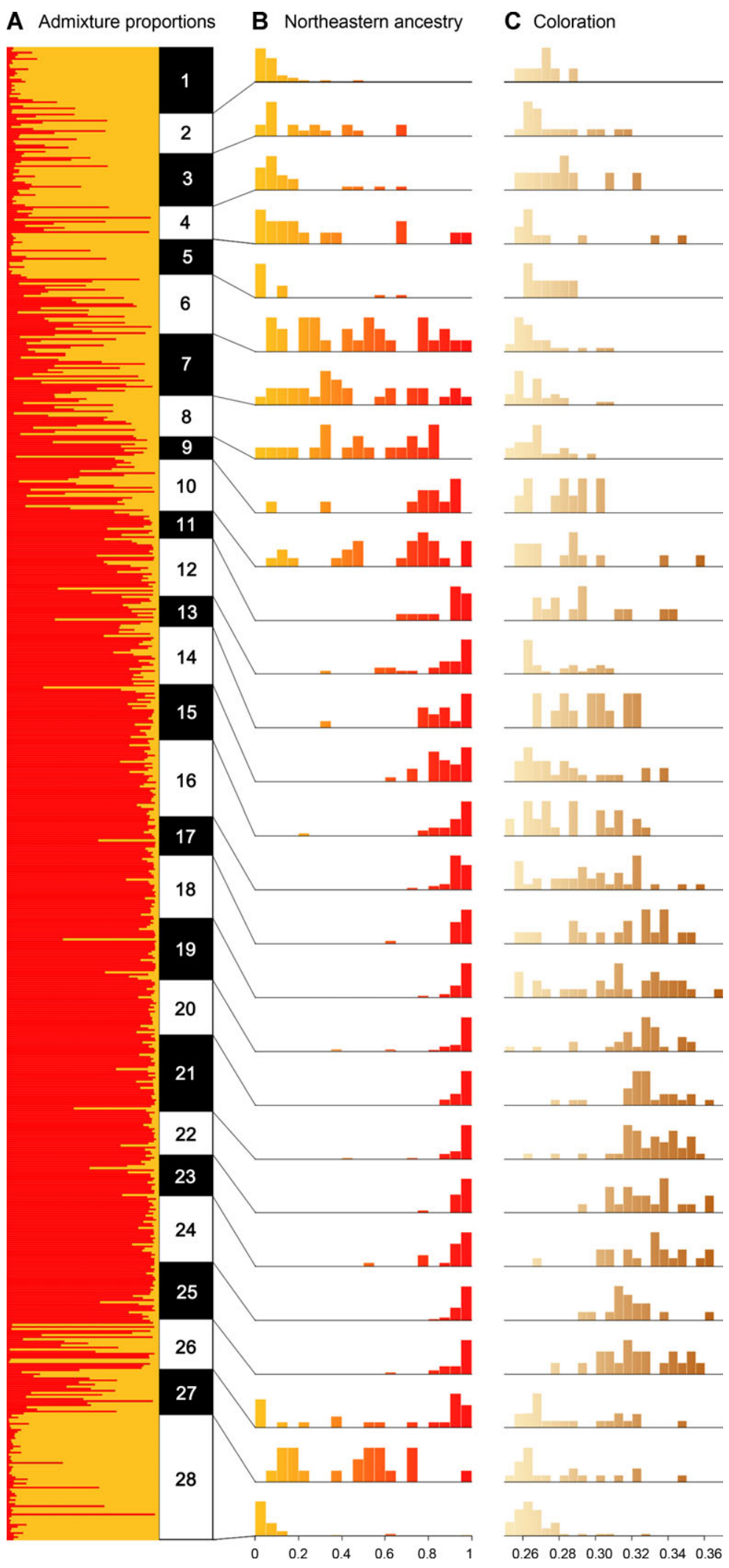

Figure 2. Admixture and color distribution per barn owl population. (A) STRUCTURE barplot. Each horizontal line represents one individual. Proportions to which each individual was assigned to the southern (orange) and northeastern (red) cluster are depicted. (B) Populationwise frequencies at which individuals were assigned to the southern (left, orange shading) and northeastern (right, red shading) clusters. (C) Population-wise color distribution (brown chroma). Legends to population numbers are provided in Figure 1 and Table S1. 
Table 1. Mantel $r$ for tests comparing classical isolation-by-distance and ring-colonization hypotheses.

\begin{tabular}{|c|c|c|c|c|c|c|c|c|c|c|}
\hline & \multicolumn{6}{|c|}{ Mantel tests } & \multicolumn{4}{|c|}{ Partial Mantel tests flight } \\
\hline & \multicolumn{3}{|c|}{ Islands included } & \multicolumn{3}{|c|}{ Islands excluded } & \multicolumn{2}{|c|}{ Islands included } & \multicolumn{2}{|c|}{ Islands excluded } \\
\hline & Flight & Land & Ring & Flight & Land & Ring & Land & Ring & Land & Ring \\
\hline Msat & $\begin{array}{c}0.616 \\
(-0.001)\end{array}$ & $\begin{array}{c}0.616 \\
(-0.001)\end{array}$ & $\begin{array}{c}0.674 \\
(-0.001)\end{array}$ & $\begin{array}{c}0.751 \\
(-0.001)\end{array}$ & $\begin{array}{c}0.777 \\
(-0.001)\end{array}$ & $\begin{array}{c}0.845 \\
(-0.001)\end{array}$ & $\begin{array}{r}0.079 \\
(-0.17)\end{array}$ & $\begin{array}{c}0.381 \\
(-0.002)\end{array}$ & $\begin{array}{c}0.326 \\
(-0.071)\end{array}$ & $\begin{array}{c}0.59 \\
(-0.001)\end{array}$ \\
\hline ND6 & $\begin{array}{c}0.441 \\
(-0.001)\end{array}$ & $\begin{array}{c}0.461 \\
(-0.001)\end{array}$ & $\begin{array}{c}0.544 \\
(-0.001)\end{array}$ & $\begin{array}{c}0.62 \\
(-0.001)\end{array}$ & $\begin{array}{c}0.632 \\
(-0.001)\end{array}$ & $\begin{array}{c}0.722 \\
(-0.001)\end{array}$ & $\begin{array}{c}0.161 \\
(-0.059)\end{array}$ & $\begin{array}{c}0.355 \\
(-0.001)\end{array}$ & $\begin{array}{r}0.159 \\
(-0.12)\end{array}$ & $\begin{array}{c}0.471 \\
(-0.013)\end{array}$ \\
\hline$M C 1 R$ & $\begin{array}{c}0.255 \\
(-0.004)\end{array}$ & $\begin{array}{c}0.184 \\
(-0.019)\end{array}$ & $\begin{array}{c}0.168 \\
(-0.061)\end{array}$ & $\begin{array}{c}0.307 \\
(-0.001)\end{array}$ & $\begin{array}{c}0.253 \\
(-0.003)\end{array}$ & $\begin{array}{c}0.25 \\
(-0.002)\end{array}$ & $\begin{array}{l}-0.349 \\
(-1)\end{array}$ & $\begin{array}{c}-0.064 \\
(-0.781)\end{array}$ & $\begin{array}{l}-0.324 \\
(-1)\end{array}$ & $\begin{array}{c}-0.029 \\
(-0.655)\end{array}$ \\
\hline Color & $\begin{array}{r}0.199 \\
(-0.01)\end{array}$ & $\begin{array}{c}0.126 \\
(-0.066)\end{array}$ & $\begin{array}{c}0.109 \\
(-0.119)\end{array}$ & $\begin{array}{c}0.356 \\
(-0.002)\end{array}$ & $\begin{array}{c}0.319 \\
(-0.001)\end{array}$ & $\begin{array}{c}0.265 \\
(-0.002)\end{array}$ & $\begin{array}{l}-0.361 \\
(-1)\end{array}$ & $\begin{array}{c}-0.088 \\
(-0.812)\end{array}$ & $\begin{array}{l}-0.34 \\
(-1)\end{array}$ & $\begin{array}{c}-0.122 \\
(0.902)\end{array}$ \\
\hline
\end{tabular}

In Mantel tests and partial Mantel test taking into account flight distance insularity was taken into account when island populations were included. $P$-values are provided in parentheses. Flight distance is denoted "Flight," shortest overland distance "Land," and ring distance "Ring."

clusters among mainland populations $(\Delta K(2)=251$, Fig. S5A$\mathrm{D})$, and for two and three clusters with islands included $(\Delta K(2)$ $=237, \Delta K(3)=331$, Fig. S5E-H). Individuals from the Middle East, North Africa, the Canary Islands, and Crete were predominantly assigned to a "southern" lineage, whereas populations from Central, Northern, and Eastern Europe formed a "northeastern" lineage $(K=2$; Fig. 2A, B). Populations from Iberia to Central Europe showed a gradual change from southern to northeastern ancestry (Fig. 2A, B). The island population from Crete was split off from the southern lineage into its own cluster at $K=3$.

To corroborate the finding of ring colonization around the Mediterranean, we performed tests that contrast alternative colonization hypotheses. Classical hypotheses of isolation by distance were modeled using distance matrices representing (i) flight distance, and (ii) shortest overland distance; ring colonization with a secondary contact zone in Greece was modeled using (iii) ring distance, that is, distance within a clockwise ring starting in the Middle East, through North Africa, Iberia, and Europe, and ending in Crete (see Fig. S1), following PCoA results (Figs. 1B, S2). Two methods that compared these models unequivocally supported the ring-colonization scenario (Tables 1,2). In linear models that related flight, overland, and ring distance from the Middle East to genetic structure measured by coordinates of the first PCo axis (PCo1), ring distance explained the highest amount of genetic structure $\left(R^{2}=0.74\right.$, Table 2 , see also Fig. $\left.1 C\right)$. Flight distance best explained the genetic structure along PCo2 $\left(R^{2}=0.40\right.$, Table 2), indicating genetic exchange among spatially close populations following colonization. In Mantel tests, pairwise flight, overland, and ring distances all significantly correlated with genetic differentiation (Table 1, Fig. S3). However, ring distance explained most of the variance (Mantel $r=0.674$, Table 1 ), also when accounting for dispersal (flight distance) among geographically close populations unrelated to colonization history (Mantel $r=0.381$, Table 1). Results were concordant between microsatellites and mitochondrial data, and not sensitive to the inclusion or exclusion of island populations (Tables 1,2 ).

\section{GENETIC DIVERSITY AND ORIGIN OF THE RING-LIKE COLONIZATION}

Colonization is expected to leave traces in the geographic distribution of neutral genetic diversity. Highest diversity was found in Southern Iberian populations (microsatellite allelic richness, $A_{\mathrm{R}}$ : Portugal, 4.60, Central Spain, 4.58) followed by Italy, Northern Spain, North Africa, and the Middle East (Fig. 1D). Lowest diversity on the mainland was found in Eastern Europe (microsatellite $A_{\mathrm{R}}$ : Hungary, 3.96; Balkans, 3.98; Brandenburg, 4.00) (Fig. 1D). Diversity is lower on islands (islands: median $A_{\mathrm{R}}=4.00$, range 3.78-4.28; mainland: median $A_{\mathrm{R}}=4.17$, range 3.96-4.60) and decreases eastwards in the north of the Mediterranean (latitude $\times$ longitude: $t=-3.84, P<10^{-3}$; insularity: $t=3.17, P=$ 0.004; longitude: $t=3.94, P<10^{-3}$; latitude: $-1.24, P=0.23$; $\left.R^{2}=0.64\right)$. Diversity also showed a strong tendency to decrease with increasing ring distance (islands included: insularity: $t=$ $-2.13, P=0.043, R^{2}=0.28$; ring distance $t=-1.80, P=$ 0.084; mainland populations: $t=-2.97, P=0.008, R^{2}=0.31$, Fig. 1D) but no relation to flight or shortest overland distance. Within the European continent, a strong significant decrease of diversity with distance from the Middle East was observed, with ring distance explaining most of the variance (ring distance: $t=-8.73$, $P<10^{-6}, R^{2}=0.82$; flight: $t=3.87, P=0.001, R^{2}=0.47$; overland: $t=5.00, P<10^{-3}, R^{2}=0.60$ ) (Fig. 1D). The same relationship was found for mitochondrial diversity $(t=-2.24$, $P=0.038, R^{2}=0.22$ ).

To infer the population with allele frequencies closest to the ancestral population, we introduced outgroup populations from 
Table 2. Correlations of principle coordinate axes with geographic variables in barn owls (R2).

\begin{tabular}{llllll}
\hline \multirow{2}{*}{ Marker } & Distance & PCoA 1 & Mainland & $\begin{array}{l}\text { PCoA 2 } \\
\text { Isl. included }\end{array}$ & Mainland \\
\hline Msat & Flight & 0.41 & 0.04 & 0.40 & 0.20 \\
& & $(0.034)$ & $(0.351)$ & $\left(<10^{-3}\right)$ & $(0.040)$ \\
& Land & 0.40 & 0.03 & 0.34 & 0.15 \\
& Ring & $(0.043)$ & $(0.476)$ & $(0.003)$ & $(0.075)$ \\
& & 0.74 & 0.76 & 0.05 & 0.01 \\
ND6 & $\left(<10^{-6}\right)$ & $\left(<10^{-6}\right)$ & $(0.825)$ & $(0.748)$ \\
& Flight & 0.23 & 0.06 & 0.01 & 0.04 \\
& & $(0.169)$ & $(0.269)$ & $(0.815)$ & $(0.394)$ \\
& Land & 0.24 & 0.04 & 0.02 & 0.04 \\
& \multirow{2}{*}{ Ring } & $(0.140)$ & $(0.360)$ & $(0.638)$ & $(0.366)$ \\
& & 0.58 & 0.59 & 0.02 & 0.07 \\
& $\left(<10^{-4}\right)$ & $\left(<10^{-4}\right)$ & $(0.561)$ & $(0.218)$ \\
\hline
\end{tabular}

When islands were included, insularity was included in the model as a factor. P-values are provided in parentheses. Flight distance is denoted "Flight," shortest overland distance "Land," and ring distance "Ring."

California, Singapore, and Australia into analyses of population structure. Both a dendrogram depicting relationships among the clusters inferred by Bayesian analyses, and $\mathrm{NJ}$ trees based on pairwise $F_{\text {ST }}$ (Fig. S6) or chord distance (not shown) between populations placed the populations from the Middle East at the root of the circum-Mediterranean colonization. Phylogenetic methods implementing nucleotide substitution models provide better estimations of long-term evolution than distance-based methods based on microsatellite data. However, Bayesian reconstruction of the phylogenetic relationships among mitochondrial ND6 haplotypes provided no further insights into the origin of ring colonization, nodes among European haplotypes having no statistical support (Fig. S6F). According to the microsatellite-based population trees (Fig. 6A-E) barn owls would appear to have first colonized the region south of the Mediterranean out of the Middle East, and later spread through Europe in a more recent expansion from Iberia (Fig. 3, see also Antoniazza et al. 2014). However, this result is to some extent opposed by the observation of highest genetic diversity on the Iberian Peninsula (although higher habitat fragmentation in the Middle East/Northeastern Africa could explain the observed pattern), and not supported by phylogenetic analysis of mitochondrial sequence data, and has therefore to be treated with caution.

\section{SECONDARY CONTACT ZONE IN SOUTHEASTERN EUROPE}

The above results place the populations from Eastern Europe and the Middle East, respectively, at the ends of a genetic continuum (irrespective of the colonization origin being situated in the Middle East or Iberia). The geographic region in-between therefore likely holds a zone of secondary contact. In line with this hypothesis, populations from Greece, the Aegean, and Crete exhibit peculiar genetic compositions reminiscent of hybrid zones: (i) microsatellite data placed these three populations at intermediate positions in PCoA (Figs. 1B, S4A), rather than with the geographically closest populations from Eastern Europe (so did also mitochondrial data for Greece and the Aegean; Fig. S2). (ii) The Greek population does not fit the otherwise strong correlation of mainland population structure with ring distance (Fig. 1C); and (iii) for Crete, relationships with other populations were discordant between microsatellites (Figs. 1B, 2A) and mitochondrial ND6 (Fig. S2).

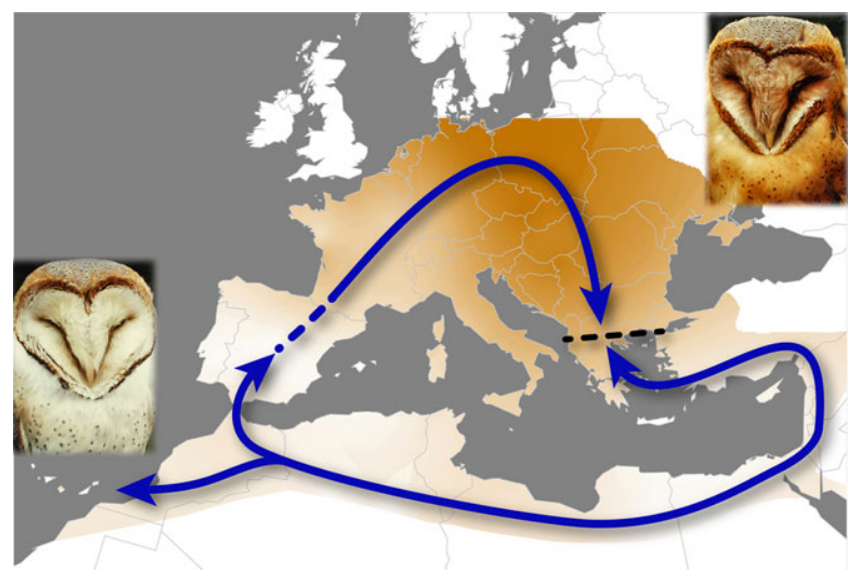

Figure 3. Circum-Mediterranean ring-like colonization of European barn owls. Arrows indicate the putative colonization routes, the black dashed line the region of secondary contact with limited introgression at microsatellites. The color gradient (interpolated using the Kriging algorithm) and typical white and rufous phenotypes are shown. 
Results from the above Bayesian clustering analyses were used to obtain further insights into patterns of admixture in Greece, the Aegean, and Crete. All Cretan individuals but four of 61 showed southern ancestry (Fig. 2A, B). In contrast, the prevalence of predominantly Northeastern European haplotypes at mitochondria (Figs. S7, S8) placed Crete unambiguously with Eastern European populations, a pattern also found for one of 22 microsatellites (Ta-220). The presence of northeastern mitochondrial variation on a predominantly southern nuclear background provides evidence for a southern ancestry of Cretan barn owls, with mitochondrial introgression from the north and more limited introgression at the nuclear level.

The Greek and Aegean populations showed a fundamentally different genetic composition than the geographically close Cretan population. Different from all other populations, individuallevel admixture appeared restricted: many individuals had either a predominantly northeastern or southern genotype (Fig. 2A, B). Although population-mean admixture was similar to Iberia (Fig. 2A, B), the population-level variance in admixture proportions in Greece and the Aegean were significantly higher than in Iberia (nonparametric bootstrap test, $P<10^{-6}$ ). The same result was found using the HI (Buerkle 2005) instead of admixture proportions (nonparametric bootstrap test, $P<10^{-6}$ ). This result indicates limited admixture between individuals from northeastern and southern origin within the secondary contact zone.

\section{LOCALLY ADAPTED CLINAL COLOR VARIATION}

Plumage coloration is sexually dimorphic with a bimodal distribution in both sexes (Fig. 4A), and showed a pronounced geographic structure. Barn owls in the south are white, whereas in Europe they get gradually darker rufous toward the east (latitude: $t=5.44$, $P<10^{-4}$; longitude: $t=-7.60, P<10^{-7}$; interaction: $t=8.02$, $P<10^{-7} ; R^{2}=0.89$ ) (Fig. 4B). Ring distance explained $22 \%$ of variation in population-mean coloration $(t=2.72, P=0.011)$, and only the Middle East, Crete, Greece, and the Aegean did not follow this stark spatial pattern (Fig. S9). With these populations excluded, ring distance alone explained $85 \%$ of color variation $\left(t=11.23, P<10^{-9}\right.$ ), which was more than explained by flight ( $\left.t=-3.76, P=0.001, R^{2}=0.39\right)$ or overland distance $\left(t=-5.28, P<10^{-5}, R^{2}=0.56\right)$.

Color differentiation among populations was marked, and followed an isolation-by-distance pattern best explained by spatial proximity (flight distance) of populations (Table 1). Although population-mean coloration reflects colonization history, color variance among populations appears to be strongly determined by the spatial proximity of populations that might reflect adaptation to a similar environment. In line with this interpretation, $F_{\mathrm{ST}}-P_{\mathrm{ST}}$ comparisons between mainland populations showed that color differentiation (overall $P_{\mathrm{ST}}=0.40$ ) exceeds predictions from neutral genetic markers (overall microsatellite $F_{\mathrm{ST}}=0.045$ ) by an order of magnitude (Fig. 5). Concordantly, $P_{\mathrm{ST}}$ differed significantly from the expected distribution of neutral differentiation at microsatellites $\left(P<10^{-15}\right)$, demonstrating that genetic drift alone cannot explain color differentiation. Differentiation at mitochondrial ND6 sequences corrected for mitochondrial effective population size was in the range of microsatellite markers, indicating that the shallow structure at microsatellites is not alone due to high diversity (Jakobsson et al. 2013). Bayesian quantitative genetic modeling (Ovaskainen et al. 2011) also rejected neutral evolution as the only driver of color differentiation $(S>$ 0.999). These results provide evidence for diversifying selection on coloration at the scale of the Western Palearctic distribution of barn owls and confirm previous results found at a smaller scale (Antoniazza et al. 2010).

\section{GENETIC BASIS AND ORIGIN OF COLORATION}

Sequencing of the MC1R gene in 671 individuals revealed a frequent nonsynonymous Ile-Val polymorphism at amino acid position 126. Heterozygotes and Ile-homozygotes were significantly more rufous than Val-homozygotes (Fig. 6). MC1R genotype, sex, and population structure (coordinates of the first axes of an individual-based PCA) together explained $65 \%$ of color variance (sex: $t=-9.89, P<10^{-15}$; individual PC1: $t=6.65, P<$ $10^{-10} ; \operatorname{MC1R}\left(\right.$ Val-Ile): $t=-4.67, P<10^{-5} ; \operatorname{MC} 1 R($ Val-Val): $\left.t=-23.66, P<10^{-15}\right)$. Analyses by population after removing the sex effect confirmed this result (Fig. S10).

To further illustrate the strong link of $M C 1 R$ with coloration, we analyzed the correlations of population structure at $M C 1 R$ with coloration, neutral genetic and spatial population structure. $M C 1 R$ allele frequencies showed a pronounced geographic structure (overall $F_{\mathrm{ST}}=0.383$, range $0-0.797$, Figs. 5, 6B, S4B), and population structure $\left(F_{\mathrm{ST}}\right)$ at $M C 1 R$ was strongly correlated with color differentiation $\left(P_{\mathrm{ST}}\right)$ (Mantel $R=0.823, P=0.001$ ), but much less with neutral genetic differentiation or spatial distances across the entire range $(\max 0.31$, Table 1$)$. Partial Mantel tests demonstrated that neither geography nor neutral genetic differentiation explain color differentiation nearly as well as $M C 1 R$ (Table 1). Moreover, Mantel tests considering only the European continent, where basically all color variation is found (Fig. 4) showed that the color variance explained by geographic distance decreases by half after removing the effect of individual $M C 1 R$ genotypes on coloration (Fig. 5A; without taking into account $M C 1 R$, Mantel $R=0.755, P=0.001$; after taking into account $M C 1 R$, Mantel $R=0.360, P=0.004)$.

Together with the significantly stronger differentiation of $M C 1 R$ than predicted from neutral genetic differentiation (Fig. 5B), this suggests that neutral evolution alone cannot explain population structure of coloration and of the underlying $M C 1 R$ genotypes. The stronger correlation of geographic structure of coloration (and $M C 1 R$ ) with spatial proximity of populations (i.e., 

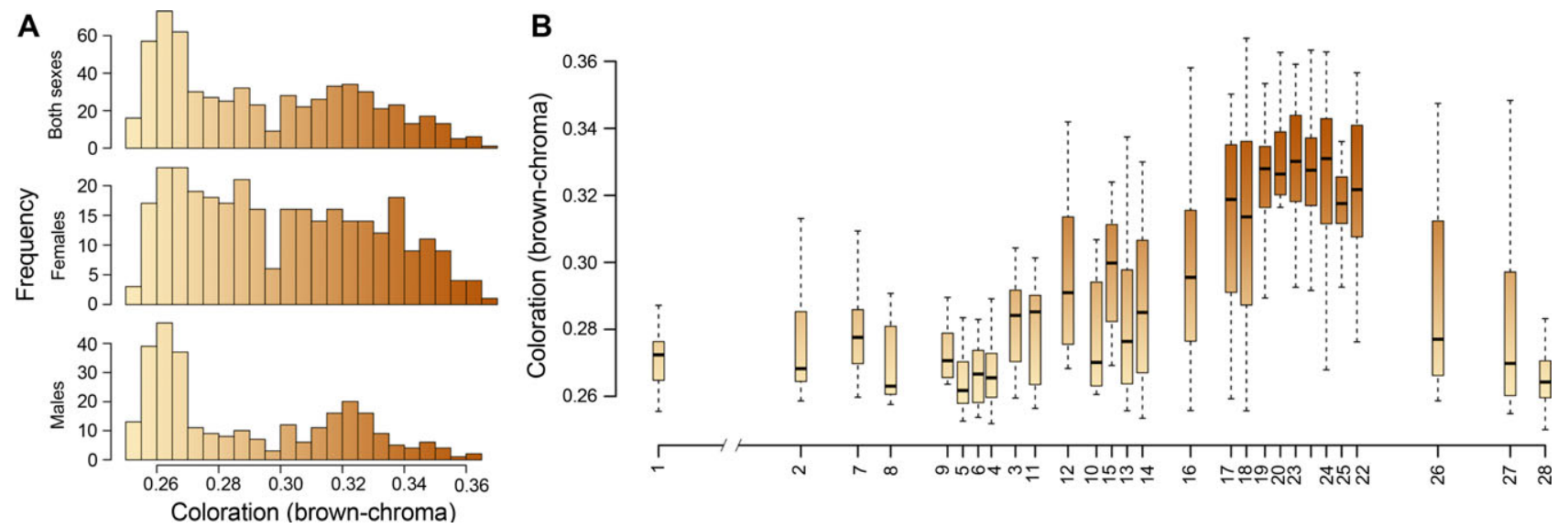

Figure 4. Color distributions in barn owls. (A) Color frequency distributions for both sexes separately and jointly. (B) Geographic distribution of coloration. Boxes are provided at approximate ring distance from the Middle East (exact distances overlap between some populations). Legends to population numbers are provided in Figure 1 and Table S1.

flight distance), rather than with ring distance (Table 1) suggests that selection mediated by locally prevailing environmental factors rather than colonization history determines the geographic structure observed for coloration and MC1R, and provides additional evidence for the local adaptation of color phenotypes.

To evaluate the relative ages of the nonsynonymous $M C 1 R$ variants, we analyzed linked genetic variation. Ten low-frequency polymorphisms linked to $M C 1 R_{\text {WHITE }}(0.2-3.1 \%$ within $M C 1 R_{\text {WHITE }}$ ) were identified from full-length (998 bp) coding sequences ( $N=870$ alleles). Conversely, only two polymorphisms were found linked to $\operatorname{MC} R_{\text {RUFOUS }}(N=252$ alleles), both occurring at minimal frequency within $M C 1 R_{\text {RUFOUS }}(0.4 \%$ and $0.8 \%$, respectively). These polymorphisms are a subset of the polymorphisms linked to $M C 1 R_{\text {WHITE }}$. Their higher frequencies on $M C 1 R_{\text {WHITE }}$ and their reticulate position in a haplotype network (Fig. S11) indicate that they originally evolved on $M C 1 R_{\text {WHITE }}$ and got linked to $M C 1 R_{R U F O U S}$ by recombination. Nonparametric bootstrap tests show that the over 10 times lower polymorphism linked to $M C 1 R_{\text {RUFOUS }}\left(\pi=2.16 \times 10^{-6}\right)$ than to $M C 1 R_{\text {WHITE }}(\pi$ $\left.=2.66 \times 10^{-5}\right)$ is not an artifact from unequal sample sizes $(P<$ $\left.10^{-6}\right)$. The significantly elevated variation linked to $M C 1 R_{\text {WHITE }}$ together with the match of this variant with the variant observed in outgroup individuals from California, Australia, and Singapore clearly establish $M C 1 R_{\text {WHITE }}$ as the ancestral variant.

Our results therefore strongly suggest that a derived nonsynonymous mutation at MC1R was involved in the evolution of a
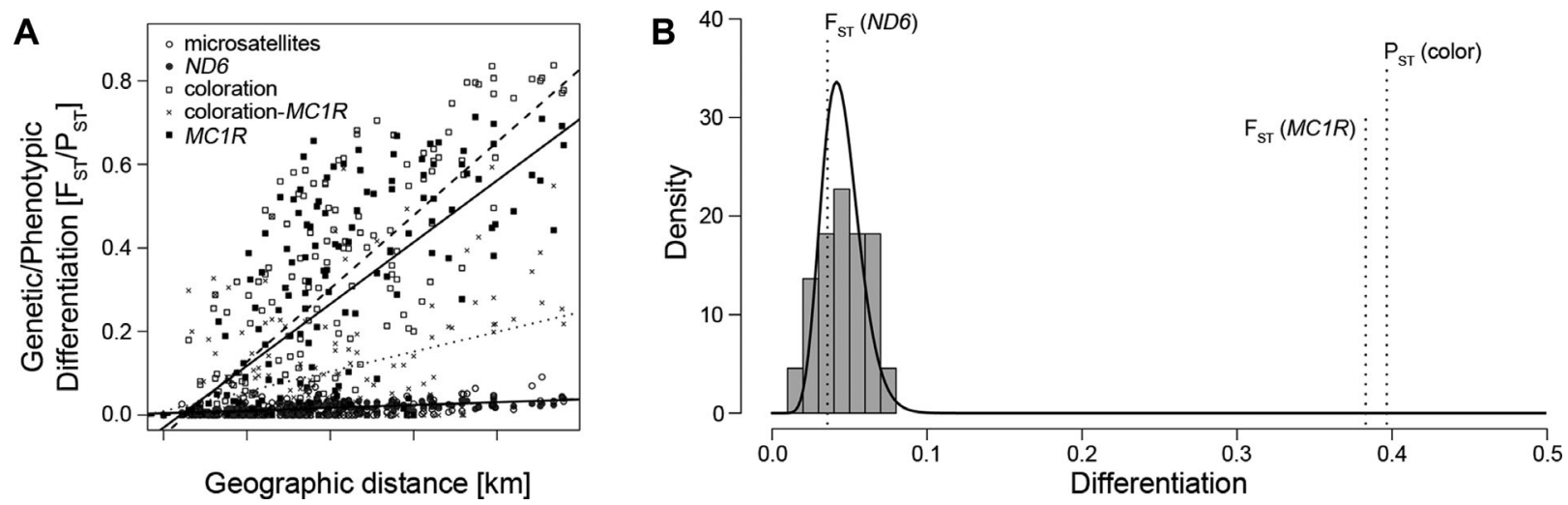

Figure 5. Comparisons of population structure at neutral genetic markers, MC1R, and coloration. (A) Pairwise genetic and phenotypic distances as a function of geographic distance within Europe. Regression lines are shown for illustrative purpose (lowest line: microsatellites and ND6, overlapping between these markers. Dashed upper line: coloration $P_{\mathrm{ST}}$. Dotted line: coloration $P_{\mathrm{ST}}$ after taking into account $M C 1 R$ genotype. Solid upper line: $M C 1 R$. (B) Overall differentiation in color $\left(P_{\mathrm{ST}}\right)$ and at $M C 1 R$ are compared against neutral genetic differentiation at microsatellite markers (gray bars) and at the mitochondrial ND6 locus. Gray bars: histogram of $F_{\mathrm{ST}}$ of the 22 microsatellite makers. Solid line: theoretical $F_{S T}$ distribution (Lewontin and Krakauer 1973). Broken lines: overall differentiation at ND6, and differentiation in color and at MC1R. In both panels differentiation at ND6 is corrected for differences in nuclear and mitochondrial effective population sizes. 


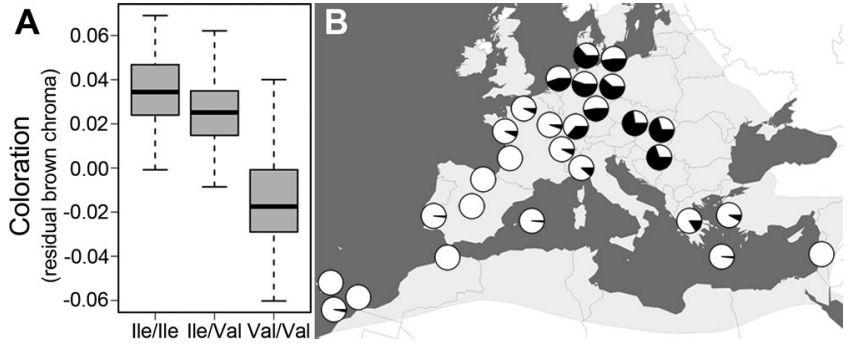

Figure 6. (A) Relationship of coloration with MC1R genotype in barn owls. Values provided for coloration are residuals after correcting brown chroma for population structure and sexual dimorphism. (B) Spatial frequency distribution of the MC1 WHHIT $_{\text {(white) }}$ and $M C 1 R_{R U F O U S}$ variants (black).

novel rufous barn owl phenotype. The lack of private variation linked to the derived $M C 1 R_{R U F O U S}$ variant together with this variant's geographic distribution (Fig. 6) indicate that it evolved either shortly before or early during the colonization of Europe

\section{LINKING COLORATION AND GENETIC ANCESTRY}

If the rufous phenotype evolved early during the colonization of Europe and is locally adapted, selection may be expected to keep it restricted to a Northeastern European genetic background. Indeed, even after taking into account sexual dimorphism, $M C 1 R$ genotype, and population structure, the genetic ancestry of individuals estimated in Bayesian analyses of population structure $(Q)$ explained a significant amount of color variation (sex: $t=-10.08$, $P<10^{-15} ; \operatorname{MClR}$ (Val-Ile): $t=-4.73, P<10^{-5} ; M C 1 R$ (ValVal): $t=-21.48, P<10^{-15} ; F_{\mathrm{ST}}: t=2.21, P=0.027 ; Q: t$ $\left.=7.65, P<10^{-13} ; R^{2}=0.67\right)$. Still, this result may establish through the spatial correlation of coloration with genetic structure, and potentially insufficient correction for genetic structure in our model. However, especially in the secondary contact zone rufous and white phenotypes are expected to be associated with predominantly northern and southern genetic ancestry, respectively, if gene flow between the terminal populations within the ring is restricted. This prediction is supported by the observation that Greece is not only where individuals of northeastern and southern ancestry meet, but is also the region with highest variance in plumage coloration (Fig. 4B).

We therefore tested whether in the secondary contact zone in Greece and the Aegean rufous coloration was associated with northeastern ancestry by estimating genetic ancestry using (i) admixture proportions $(Q)$, (ii) the first axis of an individualbased PCA, and (iii) the HI. All analyses confirmed that in the secondary contact zone darker rufous individuals have elevated northeastern ancestry (Fig. S12; $Q$ : sex: $t=-2.95, P=0.006$; $M C 1 R$ (Val-Ile): $t=-0.60, P=0.55 ; M C 1 R$ (Val-Val): $t=-2.36$, $P=0.025$; ancestry: $t=2.53, P=0.017, R^{2}=0.60$; PCA, sex: $t=-2.45, P=0.021, M C 1 R($ Val-Ile): $t=-0.74, P=0.464$;
$M C 1 R$ (Val-Val): $t=-2.49, P=0.019$, ancestry: $t=2.35, P=$ $0.026, R^{2}=0.59$; for HI, sex: $t=-2.53, P=0.017, M C 1 R$ (ValIle): $t=-0.86, P=0.397$; MClR(Val-Val): $t=-2.63, P=$ 0.013 , HI: $\left.t=-3.15, P=0.004, R^{2}=0.64\right)$. No other population showed the same consistent correlation between color and genetic ancestry. The secondary contact zone in Greece and the Aegean is thus the only region with evidence for linkage disequilibrium of coloration with neutral genetic ancestry.

\section{Discussion}

We found that European barn owls likely colonized their Western Palearctic range in a ring around the Mediterranean (Fig. 3), and that a novel rufous phenotype evolved by a coding mutation in the MCIR gene likely around the onset of colonization of Europe. Analyses of the spatial distribution of coloration and the underlying MClR variation provide evidence that the barn owl's color cline evolved by local adaptation during or following this colonization. Finally, admixture patterns and linkage disequilibrium of coloration with the neutral genetic background in Greece suggest that introgression at secondary contact is limited, uncovering a pattern reminiscent of ring species. We in turn discuss the evidence and implications of local adaptation of the color cline, and the hypothesis of circum-Mediterranean ring speciation in European barn owls.

\section{LOCAL ADAPTION: TOWARDS IDENTIFYING THE TARGET AND AGENT OF SELECTION}

Local adaptation of barn owl color phenotypes is highlighted by one of the most remarkable findings of the present study: Differentiation of color and of the underlying gene $(M C 1 R)$ is strongest in the geographic region with the weakest-indeed almost absent-population structure (Central, Northern, and Eastern Europe). Moreover, the range-wide bimodal color distribution may suggest reduced fitness of intermediate phenotypes, or a lower frequency of the habitat occupied by this phenotype (or alternatively dominance of the rufous allele). Together with quantitative genetic analyses and previous results (Antoniazza et al. $2010,2014)$ this indicates an important role for local adaptation in maintaining the geographic structure of coloration and/or linked phenotypic traits. Alongside these results the identification of $M C 1 R$ as a major-effect color QTL and the demonstration of a steep geographic gradient in $M C 1 R$ allele frequencies parallel to the color cline provide strong evidence for local adaptation, as environment cannot affect allele frequencies other than via natural selection.

Previous work on color-related adaptation identified $M C 1 R$ as a major genetic determinant of color polymorphism in a wide range of vertebrates (Våge et al. 1997; Theron et al. 2001; Mundy et al. 2004; Hoekstra et al. 2006). The identification of this gene as 
major contributor to color variation in barn owls helps understanding the evolutionary history of color adaptation in this species. $M C 1 R$ is thought to have minimal pleiotropic effects (Mundy 2005) as compared to other melanocortin receptors (Ducrest et al. 2008). Unless $M C 1 R$ has additional, yet to be described phenotypic effects, it therefore appears likely that coloration itself is the target of selection. From this perspective and as indicated by color-related diet (Roulin 2004; Charter et al. 2012), predatorprey interactions seem a likely agent of selection. Adaptation to prey is likely to involve multiple traits related to hunting and to go along with additional habitat-related adaptations. Barn owl color phenotypes may therefore be part of alternative phenotypic syndromes connected to predation that encompass an entire suit of correlated traits (see Introduction). Unless the genes encoding these traits are tightly physically linked (e.g., as a supergene in an inversion, Joron et al. 2011; Thompson and Jiggins 2014), selection for local adaptation still must act on each gene separately. Based on the currently available data, we cannot exclude such a genetic architecture of the phenotypic syndrome correlated with coloration, although the abundant evidence for $M C 1 R$ related adaptation (e.g., Hubbard et al.; Nachman et al. 2003; Rosenblum et al. 2004; Hoekstra et al. 2006; Nadeau and Jiggins 2010) may suggest that direct selection on $M C 1 R$ is a likely explanation for the strong population structure at this locus and the correlated color phenotypes. Future whole genome analyses to identify genetic variants that parallel clinal variation and explain individual variation in phenotypes (e.g., Poelstra et al. 2014) other than coloration will provide promising insights into the genetic architecture of the phenotypic syndromes.

\section{ADAPTIVE EVOLUTION FROM A NOVEL GENETIC VARIANT}

An important question in evolutionary biology addresses the origin of adaptive genetic variation: does local adaptation evolve from genetic variation segregating in populations (standing variation), or from novel, derived variants (Barrett and Schluter 2008)? Studies demonstrating local adaptation of color phenotypes and identifying the underlying genes have previously contributed remarkable insights in this respect (Hoekstra et al. 2006). The $M C 1 R_{\text {RUFOUS }}$ variant predominant in the most recently colonized northeast of Europe appears to be derived and have evolved more recently than the ancestral $M C 1 R_{\text {WHITE }}$ variant. Together with its almost complete absence in the south of the range, this suggests that the $M C 1 R_{\text {RUFOUS }}$ variant arose either shortly before or during the colonization of Central Europe. The supposition that rufous coloration is correlated to a disperser phenotype (Roulin 2004, 2013; Charter et al. 2012, 2015; Van den Brink et al. 2012) adds another interesting perspective in this context, as theoretical models suggest that increased dispersal propensity itself could have conferred rufous birds with an additional advantage during range expansion (Travis and Dytham 2002). This leads us to hypothesize that the rapid colonization of Northern and Eastern Europe by barn owls may have been triggered by the derived phenotype's ability to cope with continental environments, and accelerated by the phenotype's enhanced dispersal ability, or vice versa.

\section{CIRCUM-MEDITERRANEAN RING SPECIATION IN BARN OWLS?}

The ring-like isolation-by-distance pattern around the Mediterranean and limited introgression at secondary contact observed in European barn owls are reminiscent of ring species. Ideal ring species consist of populations with a ring-like distribution around a geographic barrier that are interconnected by gene flow throughout the ring, vary gradually in phenotypic traits, and display full reproductive isolation at secondary contact (Irwin et al. 2001a). As yet, none of the few proposed ring species withheld scrutinous examination (Irwin et al. 2001a,b, 2005; Joseph et al. 2008; Kuchta et al. 2009). Even in the prime example of greenish warblers (Phylloscopus trochiloides), recent genome-wide data demonstrated multiple breaks in gene flow in the history of the ring (Alcaide et al. 2014) . However, while for greenish warblers deep phylogeographic breaks in mitochondrial variation (Irwin et al. 2001b) gave hints into this direction, barn owls display only gradual shifts in mitochondrial haplotype frequencies. Current data thus suggest that barn owls may withstand the criterion of continuously interconnected populations. However evidence for reproductive isolation at secondary contact is limited and indirect. Future detailed investigations, including ecological and behavioral studies in the secondary contact zone and comprehensive coalescent modeling using genome-wide data will have to provide further insights into the extent and nature of reproductive isolation at secondary contact and refine the picture of population structure across the ring, before a revival of ring species.

\section{ACKNOWLEDGMENTS}

We thank Associate Editor R. Brumfield, A. Buerkle, T. Kawakami, P. Nosil, A. Shafer, and anonymous reviewers for comments on previous versions of the article; M. Stöck, A. Cibois, and R. Tomé for help with establishing contacts; and L. Clément and V. Uva for laboratory assistance. R. Alonso, M. Cozzo, the Natural History Museums in Frankfurt and Munich, A. Häller, B. Hartung, M. Hug, G. Klammer, G. Linde, J. Luge, G. Moyne, P. L. Pap, O. Schmidt, and F. Valera provided additional samples. We are indebted to the Wildlife Rehabilitation Centres La Tahonilla (Cabildo de Tenerife), Tafira (Cabildo de Gran Canaria), and the Biological Station of La Oliva (Cabildo de Fuerteventura), and the Natural History Museum of Tenerife and Gustavo Tejera (Lanzarote) for providing tissue samples from the Canary Islands. The authors thank ANIMA (Athens, Greece), the Natural History Museum Paris, and the Association CHENE for collaboration, and M. Karhunen for assistance with RAFM and Driftsel. Financial support was provided by the Swiss National Science Foundation, grants 31003A_120517 to AR, 31003A_138180 to JG, and PBLAP3-140171 and PBLAP3-134299 to RB, and the Fondation Agassiz to AR. 


\section{DATA ARCHIVING}

Microsatellite, mitochondrial ND6, and MC1R genotypes, and coloration data available from the Dryad Digital Repository (http://dx.doi.org/10.5061/dryad.2d53k). Mitochondrial and MC1R haplotypes were deposed on GenBank (accession numbers KU143929KU143967).

\section{LITERATURE CITED}

Alcaide, M., E. S. C. Scordato, T. D. Price, and D. E. Irwin. 2014. Genomic divergence in a ring species complex. Nature 511:83-85.

Antoniazza, S., R. Burri, L. Fumagalli, J. Goudet, and A. Roulin. 2010. Local adaptation maintains clinal variation in melanin-based coloration of European barn owls (Tyto alba). Evolution 64:1944-1954.

Antoniazza, S., R. Kanitz, S. Neuenschwander, R. Burri, A. Gaigher, A Roulin, and J. Goudet. 2014. Natural selection in a postglacial range expansion: the case of the colour cline in the European barn owl. Mol. Ecol. 23:5508-5523

Barrett, R. D. H., and D. Schluter. 2008. Adaptation from standing genetic variation. Trends Ecol. Evol. 23:38-44.

Brommer, J. E. 2011. Whither Pst? The approximation of Qst by Pst in evolutionary and conservation biology. J. Evol. Biol. 24:1160-1168.

Buerkle, C. A. 2005. Maximum-likelihood estimation of a hybrid index based on molecular markers. Mol. Ecol. Notes 5:684-687.

Burri, R., S. Antoniazza, F. Siverio, A. Klein, A. Roulin, and L. Fumagalli. 2008. Isolation and characterization of 21 microsatellite markers in the barn owl (Tyto alba). Mol. Ecol. Resour. 8:977-979.

Cavalli-Sforza, L. L., and A. W. F. Edwards. 1967. Phylogenetic analysis: models and estimation procedures. Am. J. Hum. Genet. 19:233-257.

Charter, M., O. Peleg, Y. Leshem, and A. Roulin. 2012. Similar patterns of local barn owl adaptation in the Middle East and Europe with respect to melanic coloration. Biol. J. Linn. Soc. 106:447-454.

Charter, M., Y. Leshem, I. Izhaki, and A. Roulin. 2015. Pheomelanin-based colouration is correlated with indices of flying strategies in the barn owl. J. Ornithol. 156:309-312.

Clement, M., D. Posada, and K. Crandall. 2000. TCS: a computer program to estimate gene genealogies. Mol. Ecol. 9:1657-1660.

Dreiss, A. N., S. Antoniazza, R. Burri, L. Fumagalli, C. Sonnay, C. Frey, J. Goudet, and A. Roulin. 2012. Local adaptation and matching habitat choice in female barn owls with respect to melanic coloration. J. Evol. Biol. 25:103-114.

Ducrest, A.-L., L. Keller, and A. Roulin. 2008. Pleiotropy in the melanocortin system, coloration and behavioural syndromes. Trends Ecol. Evol. 23:502-510

Earl, D. A., and B. M. vonHoldt. 2012. STRUCTURE HARVESTER: a website and program for visualizing STRUCTURE output and implementing the Evanno method. Conserv. Genet. Resour. 4:359-361.

Evanno, G., S. Regnaut, and J. Goudet. 2005. Detecting the number of clusters of individuals using the software STRUCTURE: a simulation study. Mol. Ecol. 14:2611-2620.

Gompert, Z., and A. C. Buerkle. 2010. introgress: a software package for mapping components of isolation in hybrids. Mol. Ecol. Resour. 10:378384.

Goslee, S. C., and D. L. Urban. 2007. The ecodist package for dissimilaritybased analysis of ecological data. J. Stat. Softw. 22:1-19.

Goudet, J. 2005. HIERFSTAT, a package for R to compute and test hierarchical F-statistics. Mol. Ecol. Notes 5:184-186.

Hoekstra, H. E. 2006. Genetics, development and evolution of adaptive pigmentation in vertebrates. Heredity 97:222-234.

Hoekstra, H. E., R. J. Hirshmann, R. A. Bundey, P. A. Insel, and J. P. Crossland. 2006. A single amino acid mutation contributes to adaptive beach mouse color pattern. Science 313:101-104.
Hubbard, J. K., J. A. C. Uy, M. E. Hauber, H. E. Hoekstra, and R. J. Safran. 2010. Vertebrate pigmentation: from underlying genes to adaptive function. Trends Genet. 26:231-239.

Hudson, D. H., and D. Bryant. 2006. Application of phylogenetic networks in evolutionary studies. Mol. Biol. Evol. 23:254-267.

Irwin, D., J. Irwin, and T. Price. 2001a. Ring species as bridges between microevolution and speciation. Genetica 112-113:223-243.

Irwin, D. E., S. Bensch, J. H. Irwin, and T. D. Price. 2005. Speciation by distance in a ring species. Science 307:414-416.

Irwin, D. E., S. Bensch, and T. D. Price. 2001b. Speciation in a ring. Nature 409:333-337.

Jakobsson, M., M. D. Edge, and N. A. Rosenberg. 2013. The relationship between $\mathrm{F}_{\mathrm{ST}}$ and the frequency of the most frequent allele. Genetics 193:515-528.

Jombart, T., S. Devillard, A.-B. Dufour, and D. Pontier. 2008. Revealing cryptic spatial patterns in genetic variability by a new multivariate method. Heredity 101:92-103.

Joron, M., L. Frezal, R. T. Jones, N. L. Chamberlain, S. F. Lee, C. R. Haag, A. Whibley, M. Becuwe, S. W. Baxter, L. Ferguson, et al. 2011. Chromosomal rearrangements maintain a polymorphic supergene controlling butterfly mimicry. Nature 477:203-206.

Joseph, L., G. Dolman, S. Donnellan, K. M. Saint, M. L. Berg, and A. T. D. Bennett. 2008. Where and when does a ring start and end? Testing the ring-species hypothesis in a species complex of Australian parrots. Proc. R. Soc. B: Biol. Sci. 275:2431-2440.

Karhunen, M., and O. Ovaskainen. 2012. Estimating population-level coancestry coefficients by an admixture F model. Genetics 192:609-617.

Karhunen, M., J. Merilä, T. Leinonen, J. M. Cano, and O. Ovaskainen. 2013. driftsel: an R package for detecting signals of natural selection in quantitative traits. Mol. Ecol. Resour. 13:746-754.

Klein, Á., G. J. Horsburgh, C. Küpper, Á. Major, P. L. M. Lee, G. Hoffmann, R. Mátics, and D. A. Dawson. 2009. Microsatellite markers characterized in the barn owl (Tyto alba) and of high utility in other owls (Strigiformes: AVES). Mol. Ecol. Resour. 9:1512-1519.

Kuchta, S. R., D. S. Parks, R. L. Mueller, and D. B. Wake. 2009. Closing the ring: historical biogeography of the salamander ring species Ensatina eschscholtzii. J. Biogeogr. 36:982-995.

Leinonen, T., R. B. O’Hara, J. M. Cano, and J. Merila. 2008. Comparative studies of quantitative trait and neutral marker divergence: a meta-analysis. J. Evol. Biol. 21:1-17.

Leinonen, T., R. J. S. McCairns, R. B. O’Hara, and J. Merila. 2013. QSTFST comparisons: evolutionary and ecological insights from genomic heterogeneity. Nat. Rev. Genet. 14:179-190.

Lewontin, R. C., and J. Krakauer. 1973. Distribution of gene frequency as a test of theory of selective neutrality of polymorphisms. Genetics 74:175195.

Librado, P., and J. Rozas. 2009. DnaSP v5: a software for comprehensive analysis of DNA polymorphism data. Bioinformatics 25:1451-1452.

McKay, J. K., and R. G. Latta. 2002. Adaptive population divergence: markers, QTL and traits. Trends Ecol. Evol. 17:285-291.

Merilä, J., and P. Crnokrak. 2001. Comparison of genetic differentiation at marker loci and quantitative traits. J. Evol. Biol. 14:892-903.

Montgomerie, R. 2006. Analysing colors. Pp. 90-147 in Hill G. E. and K. J. McGraw., eds. Bird coloration. Mechanisms and measurements. Harvard Univ. Press, London.

Mundy, N. I. 2005. A window on the genetics of evolution: MC1R and plumage colouration in birds. Proc. R. Soc. B: Biol. Sci. 272:16331640 .

Mundy, N. I., N. S. Badcock, T. Hart, K. Scribner, K. Janssen, and N. J. Nadeau. 2004. Conserved genetic basis of a quantitative plumage trait involved in mate choice. Science 303:1870-1873. 
Nachman, M. W., H. E. Hoekstra, and S. L. D'Agostino. 2003. The genetic basis of adaptive melanism in pocket mice. Proc. Natl. Acad. Sci. USA 100:5268-5273.

Nadeau, N. J., and C. D. Jiggins. 2010. A golden age for evolutionary genetics? Genomic studies of adaptation in natural populations. Trends Genet. 26:484-492.

Nosil, P. 2012. Ecological speciation. Oxford Univ. Press, Oxford, U.K.

Ovaskainen, O., M. Karhunen, C. Zheng, J. M. C. Arias, and J. Merilä. 2011. A new method to uncover signatures of divergent and stabilizing selection in quantitative traits. Genetics 189:621-632.

Poelstra, J. W., N. Vijay, C. M. Bossu, H. Lantz, B. Ryll, I. Müller, V. Baglione, P. Unneberg, M. Wikelski, M. G. Grabherr, et al. 2014. The genomic landscape underlying phenotypic integrity in the face of gene flow in crows. Science 344:1410-1414.

Pritchard, J. K., M. Stephens, and P. Donnelly. 2000. Inference of population structure using multilocus genotype data. Genetics 155:945-959.

Py, I., A.-L. Ducrest, N. Duvoisin, L. Fumagalli, and A. Roulin. 2006. Ultraviolet reflectance in a melanin-based plumage trait is heritable. Evol. Ecol. Res. 8:483-491.

Ronquist, F., M. Teslenko, P. van der Mark, D. L. Ayres, A. Darling, S. Höhna, B. Larget, L. Liu, M. A. Suchard, and J. P. Huelsenbeck. 2012. MrBayes 3.2: efficient Bayesian phylogenetic inference and model choice across a large model space. Syst. Biol. 61:539-542.

Rosenblum, E. B., H. E. Hoekstra, and M. W. Nachman. 2004. Adaptive color variation and the evolution of the MC1R gene. Evolution 58:1794-1808.

Roulin, A. 2003. Geographic variation in sexual dimorphism in the barn owl Tyto alba: a role for direct selection or genetic correlation? J. Avian Biol. 34:251-258.

- 2004. Covariation between plumage color polymorphism and diet in the barn owl Tyto alba. Ibis 146:509-517.

- 2013. Ring recoveries of dead birds confirm that darker pheomelanic barn owls disperse longer distances. J. Ornithol. 154:871-874.

Roulin, A., and C. Dijkstra. 2003. Genetic and environmental components of variation in eumelanin and phaeomelanin sex-traits in the barn owl. Heredity 90:359-364.

Roulin, A., and A.-L. Ducrest. 2013. Genetics of colouration in birds. Semin. Cell Dev. Biol. 24:594-608.

Roulin, A., C. Dijkstra, C. Riols, and A.-L. Ducrest. 2001. Female- and malespecific signals of quality in the barn owl. J. Evol. Biol. 14:255-266.

Roulin, A., J. Gasparini, P. Bize, M. Ritschard, and H. Richner. 2008. Melanin-based colorations signal strategies to cope with poor and rich environments. Behav. Ecol. Sociobiol. 62:507519.

Roulin, A., M. Wink, and N. Salamin. 2009. Selection on a eumelanic ornament is stronger in the tropics than in temperate zones in the worldwidedistributed barn owl. J. Evol. Biol. 22:345-354.

Roulin, A., A. Da Silva, and C. A. Ruppli. 2012. Dominant nestlings displaying female-like melanin coloration behave altruistically in the barn owl. Anim. Behav. 84:1229-1236.

Stearns, S. C. 1992. The evolution of life histories. Oxford Univ. Press, Oxford, U.K.

Stephens, M., N. J. Smith, and P. Donnelly. 2001. A new statistical method for haplotype reconstruction from population data. Am. J. Hum. Genet. 68:978-989.

Theron, E., K. Hawkins, E. Bermingham, R. E. Ricklefs, and N. I. Mundy. 2001. The molecular basis of an avian plumage polymorphism in the wild: a melanocortin-1-receptor point mutation is perfectly associated with the melanic plumage morph of the bananaquit, Coereba flaveola. Curr. Biol. 11:550-557.

Thompson, J. D., D. G. Higgins, and T. J. Gibson. 1994. CLUSTAL W: improving the sensitivity of progressive multiple sequence alignment through sequence weighting, position-specific gap penalties and weight matrix choice. Nucleic Acids Res. 22:4673-4680.

Thompson, M. J., and C. D. Jiggins. 2014. Supergenes and their role in evolution. Heredity 113:1-8.

Travis, J. M., and C. Dytham. 2002. Dispersal evolution during invasions. Evol. Ecol. Res. 4:1119-1129.

Våge, D. I., D. Lu, H. Klungland, S. Lien, S. Adalsteinsson, and R. D. Cone. 1997. A non-epistatic interaction of agouti and extension in the fox, Vulpes vulpes. Nat. Genet. 15:311-315.

Van den Brink, V., A. N. Dreiss, and A. Roulin. 2012. Melanin-based coloration predicts natal dispersal in the barn. Anim. Behav. 84:805812.

Whitlock, M. C. 2008. Evolutionary inference from Q(ST). Mol. Ecol. 17:1885-1896.

Whitlock, M. C., and F. Guillaume. 2009. Testing for spatially divergent selection: comparing QST to FST. Genetics 183:1055-1063.

Yannic, G., R. Burri, V. G. Malikov, and P. Vogel. 2012. Systematics of snow voles (Chionomys, Arvicolinae) revisited. Mol. Phylogenet. Evol. 62:806-815.

Associate Editor: R. Brumfield Handling Editor: R. Shaw

\section{Supporting Information}

Additional Supporting Information may be found in the online version of this article at the publisher's website:

Table S1. Population sample sizes, sample sizes for genetic markers and color phenotypes, and ring distance from the Middle East.

Table S2. Microsatellite multiplex sets.

Figure S1. Alternative distance models.

Figure S2. Principle coordinate analysis based on population differentiation $\left(\mathrm{F}_{\mathrm{ST}}\right)$ at mitochondrial ND6 in the barn owl.

Figure S3. Isolation-by-distance patterns for different distance models in the barn owl.

Figure S4. Neighbor-joining trees based on pairwise population differentiation ( $\mathrm{F}_{\mathrm{ST}}$ ) estimated from (A) 22 nuclear microsatellite markers and (B) allele frequencies at $M C 1 R$ amino acid position 126 in the barn owl.

Figure S5. STRUCTURE results for mainland populations only (A-D) and for all populations (E-H).

Figure S6. Population trees among European mainland populations rooted with outgroup populations from the United States and Oceania (Australia and Singapore).

Figure S7. Spatial frequency distribution of mitochondrial ND6 haplotypes in the barn owl.

Figure S8. Mitochondrial ND6 haplotype network in the barn owl.

Figure S9. Spatial distribution of populations' mean coloration along the circum-Mediterranean ring in the barn owl.

Figure S10. Population-wise relationships of coloration with $M C 1 R$ genotype in the barn owl.

Figure S11. NeighborNet haplotype network of $M C 1 R$ haplotypes.

Figure S12. Correlations of coloration with genetic ancestry in the secondary contact zone (Greece and Aegean). 